\title{
Neuroendocrine tumors of the ovary: What support?
}

\author{
H. Al Moubaker ${ }^{1}$, S. Errarhay ${ }^{1}$, S. Mahmoud ${ }^{1}$, Amal Bennani ${ }^{2}$, C. Bouchikhi ${ }^{1}$, \\ Affaf Amarti ${ }^{2}$, A. Banani ${ }^{1}$ \\ ${ }^{1}$ Service Gynecology Obstetricsi Chuhassan Iifes, Fez, Morocco \\ ${ }^{2}$ Service Pathological Anatomy Chuhassan Iifes, Fez, Morocco \\ Email: suine_err@yahoo.fr
}

Received 20 November 2013; revised 12 December 2013; accepted 20 December 2013

Copyright @ 2013 H. Al Moubaker et al. This is an open access article distributed under the Creative Commons Attribution License, which permits unrestricted use, distribution, and reproduction in any medium, provided the original work is properly cited. In accordance of the Creative Commons Attribution License all Copyrights (C) 2013 are reserved for SCIRP and the owner of the intellectual property H. Al Moubaker et al. All Copyright (c) 2013 are guarded by law and by SCIRP as a guardian

\begin{abstract}
Neuroendocrine tumors of the ovary tumors are little known and infrequent. They are made up of cells appearing in the endocrine and nervous systems. These tumors are rare, but most of them are very aggressive, especially when they are diagnosed beyond FIGO Stage I. The distinction among the different subtypes is difficult and requires efficient techniques. Symptoms of neuroendocrine tumors are often nonspecific (redness in the face, diarrhea, asthma, abdominal pain and etc.,) and confused with more common diseases. Misdiagnosis is often asked: menopause or irritable bowel syndrome. Often the correct diagnosis is not made until years after the onset of symptoms. The relative rarity of these diseases and the lack of specificity of the symptoms make them often be diagnosed several years after onset. Fortunately, science has made significant advances in the diagnosis and treatment of neuroendocrine tumors. We report the case of a woman of 54 years, with abdominopelvic mass, in whom abdominal ultrasound revealed a mass avascular tissue Doppler taking the screen. The abdominopelvic CT showed a large cystic mass solidoabdominopelvic whose origin is difficult to determine. The patient underwent an exploratory laparotomy. Anapath the results of the right ovary were in favor of a well-differentiated neuroendocrine lesion.
\end{abstract}

Keywords: Tumor

Neuroendocrine-Diagnosis-Treatment

\section{INTRODUCTION}

Neuroendocrine tumors are tumors that develop from hormone-producing cells located in the endocrine (hormonal) system and the nervous system [1].
During their growth, these tumors, in some cases, produce more hormones. Others are called non-secreting: although formed from neuroendocrine cells, they do not produce hormones.

Carcinoid tumors represent $0.1 \%$ of organic lesions of the ovary. This type of tumor, resulting in germ cells, is considered in the WHO classification as a highly specialized teratoma. A mature teratoma is associated in $75 \%$ of cases $[2,3]$.

These particular tumors can metastasize easily. Most are formed in the gut and the lung, but are found elsewhere in the body. The members have functions of glands. Although there are many types of neuroendocrine tumor, they are treated as a separate group because the cells of these tumors have several common features: they are physically quite similar neoplasms and produce a secretory granule often with a production biogenic amines and hormones (polypeptides). We can distinguish four groups of carcinoid tumors of the ovary: the insular carcinoid, trabecular, and mucinous stroma .

\section{OBSERVATION}

54-years-old patient, single, no significant pathological history, which has pelvic pain associated with a progressive increase in abdominal volume, in which the clinical examination is a farm abdomino-pelvic mass, fixed, two finger breadths above the umbilicus, the rest of the examination was normal.

Abdominal ultrasound revealed a mass non-vascularized tissue Doppler taking the screen, the uterus and annexes seen.

The abdomino-pelvic CT objectified an important solido-abdominopelvic cystic mass whose origin is difficult to determine. (Figure 1)

The patient underwent an exploratory laparotomy showing an increased uterus size by 20 weeks of gesta- 

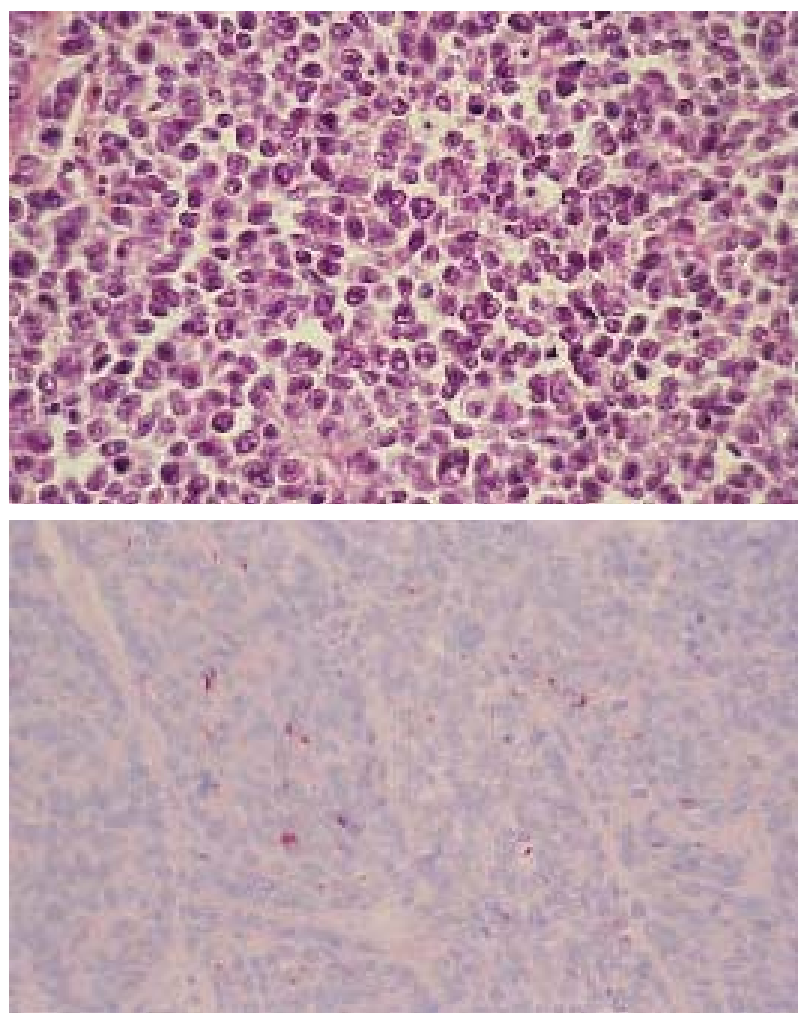

Figure 1. Clearlydifferentiatedneuroendocrine tumor $(\times 10)$.

tion seat multiple myomas, the largest landlocked is earlier in the right broad ligament, the 2 annexes were unremarkable .

A total hysterectomy with bilateral salpingo-oophorectomy were performed and the cell proliferation and histological immunohistochemical analysis was in favor of a well-differentiated neuroendocrine lesion on the right ovary (Figure 2). The patient underwent clinical monitoring was unremarkable for a year.

\section{DISCUSSION}

The neuroendocrine tumors are classified according to several criteria: location of the tumor; type of secretion of tumor (or lack of secretion); level of proliferation: speed cell division; level of differentiation of cells: cancer cells are they close to normal cell or have they lost their basic characteristics; size of the tumor and the presence or absence of metastases; etc.

The diagnosis is difficult and of ten delayed [4]. Several factors are responsible for the late diagnosis of neuroendocrine tumors: slow evolution, primary tumor of ten small and little talking symptoms.

The symptoms of neuroendocrine tumors are nonspecific. These slow-growing tumors are often confused with more common diseases. This feature, as well as their relative rarity, they are often diagnosed several years after onset. Fortunately, research evolves impress-
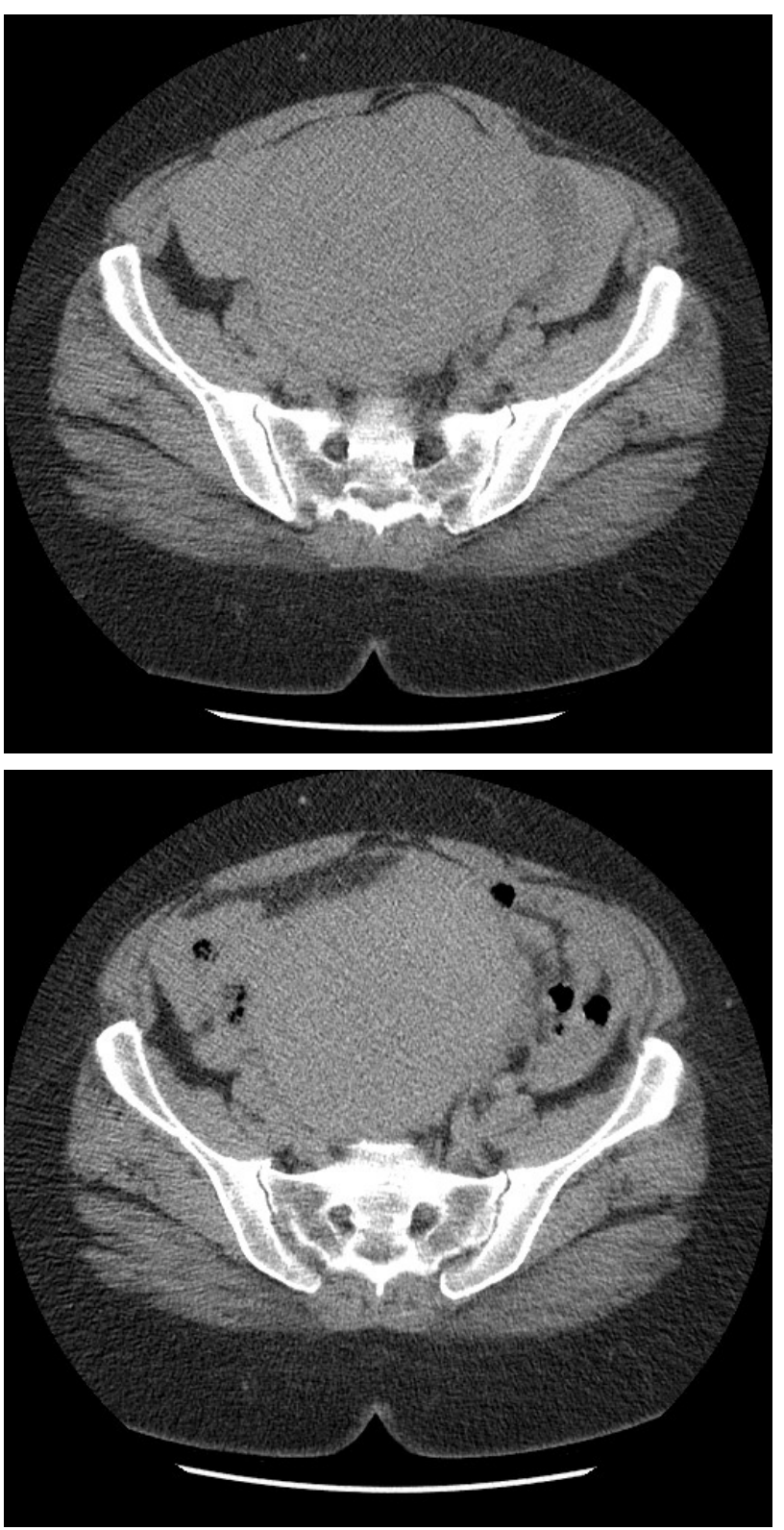

Figure 2. AbdominopelvicCT: A massive mass abdominopelvic solido-cystic.

sive in the diagnosis and management of these tumors [5-7].

Some of these tumors secrete substances such as serotonin and may be responsible for: episodes of redness in the face and neck (flushing); episodes of infectious diarrhea without cause; asthma attacks; abdominal pain ; red digestive after meals ; chest pain etc.

However, there are some symptoms that typical and often attributed to other illnesses such as irritable bowel syndrome or Crohn's disease [6], for example. Furthermore $50 \%$ of neuroendocrine tumors are not accompanied by these symptoms and are therefore diagnosed only when their size becomes too large or by chance during 
gastrointestinal or pulmonary examinations.

In recent years, specific blood tests have been developed and proved to be very useful in the diagnosis and monitoring of neuroendocrine tumors [8-10]. Various hormones can be secreted by type of neuroendocrine tumor. In addition, it is very difficult to dose dozens of hormones that may be secreted by a neuroendocrine tumor. Special substance called chromogranin A seems to be commonly found in the blood sample, regardless of the location and type of neuroendocrine tumor. In case of increased blood levels of the chromogranin, dosages of specific hormones can be considered to specify what type of tumor neuroencocrine it is.

The majority of neuroendocrine tumors secretes a substance called serotonin. As blood serotonin level varies during the day, its measurement is unreliable. For cons, the measurement in urine collected for 24 hours a substance derived from serotonin, acid-5-hydroxyindole (5 HIAA), may be useful in diagnosis.

Colonoscopies are more frequently used in screening for colon cancer. A neuroendocrine tumor can therefore be discovered by chance during an examination of this type [11,12].

Colonoscopy also allows, in case of discovery of a tumor, to take to make microscopic analysis a piece of it by biopsy. This deduction can confirm the diagnosis.

CT and magnetic resonance canlocate the neuro-endocrine tumor; determine the size of the tumor; whether there are metastases in other organs such as the liver. Both tests, however, are limited by the size of the tumor [13-15].

Isotopic consideration (scintigraphy) is injected into the circulation of the patient and the radioactive octreotide measuring cell activity [14].

In the context of neuroendocrine tumors, the injected product is called somatostatin. This product binds to the majority of cancer cells neuroendocrine tumors. We can in this way determine if treatment with octreotide is possible.

Many parameters will influence the choice of treatment. We must first keep in mind that more than half of neuroendocrine tumors have metastasized at diagnosis. This is partly due to the fact that it often takes several years before the diagnosis.

The treatment therefore concerns not only the primary tumor but also any metastases and symptoms often present for some time.

If the tumor is diagnosed early enough, and therefore localized and small, a cure can sometimes be considered. This treatment will be achieved by surgical removal of the tumor. In other cases, if the primary tumor is larger or if there are metastases, the goal is to stabilize the tumor progression and improve quality of life of the patient.

The patient's age, background, his general health, are parameters that will influence the choice of treatment.

Surgery plays an important role in the treatment of neuroendocrine tumors. It has three objectives:

- healing when possible; When neuroendocrine tumor is localized and small, curative surgery may be considered. It is to remove the entire tumor.

- improving the quality of life of the patient; Someneuroendocrine tumors are large, for example, block the digestive tract and prevent the passage of stool. An operation is then performed to relieve the patient.

- support some metastases: liver metastases (liver) are common. Surgery can help remove one or more liver metastases. Unlike some tumors very rapidly changing the surgical treatment of metastatic neuroendocrine tumors is one of the mainstays of treatment [16-18].

In the case of ovarian tumor, Standard surgical principles apply for neuroendocrine tumors.

However, for young patients with an ovarian tumor isolated, conservative surgery of fertility may be considered in combination with adjuvant chemotherapy. This chemotherapy is generally based on platinum derivatives and drugs etoposide.

Availability since $1988(16,18)$ Octreotide has significantly changed the management of patients with neuroendocrine tumors (NET). Octreotide is a somatostatin analog. After octreotide, other somatostatin analogs such as lanreotide, have appeared.

Scientists recent studies have shown that ocrétotide allow stabilization of the tumor. It is reserved for patients in whom the tumor can not be treated by simple surgical resection. The drug slows the growth of cancer cells and reduces the risk of tumor progression by $66 \%$ compared to placebo.

Octreotide and lanreotide also seem to have an effect on certain symptoms such as episodes of flushes (sudden redness in the face and neck) and diarrhea.

Many other treatments are sometimes offered to patients with neuroendocrine tumors: radiotherapy, chemotherapy, liver transplant, etc.

Prognosis: well-differentiated neuroendocrine tumors have a slow evolution, long time locally contrast to undifferentiated tumors. The risk of lymph node metastasis and visceral extension is important when the tumor is large and when the mitotic activity is greater. The visceral metastases are usually hepatic. Survival is related with the degree of differentiation.

\section{CONCLUSIONS}

The discovery of a neuroendocrine tumor is difficult to live, with regard to the rarity of this tumor and the lack of information available. However, many patients are relieved to finally have found the cause of the symptoms they suffer for several years. 
Neuroen docrine tumors are often growing slowly. Paradoxically, this slow evolution is often responsible for late diagnosis. Upon detection of neuroendocrine tumor is often add that the existence of metastases.

Fortunately, research evolves impressive in the diagnosis and management of these tumors. Moreover, their relatively good prognosis for some of them can hope.

\section{REFERENCES}

[1] Capella, C., Heitz, P.U., Höffler, H., Solcia, E. and Klöppel, G. (1995) Revised classification of neuroendocrine tumours of the lung, pancreas and gut. Virchows Archiv, 425, 547-560. http://dx.doi.org/10.1007/BF00199342

[2] Pearse, A.G.E. (1969) The cytochemistry and ultrastructure of polypeptide hormone-producing cells of the APUD series, and the embryologic, physiologic and pathologic implications of the concept. Journal of Histochemistry \& Cytochemistry, 17, 303-313. http://dx.doi.org/10.1177/17.5.303

[3] Le Douarin, N.M., Teillet, M.A. and Couly, G. (1990) Chimères embryonnaireset développement du système nerveux. Medecine Sciences, 6, 228-244.

[4] Andrew, A., Kramer, B. and Rawdon, B. (1998) The origin of gut and pancreatic neuroendocrine (APUD) cellsthe last word? The Journal of Pathology, 186, 117-118. http://dx.doi.org/10.1002/(SICI)1096-9896(1998100)186: 2<117::AID-PATH152>3.0.CO;2-J

[5] Lechago, J. and Gould, V.E. (1997) Blood worth's endocrine pathology, 3rd Edition, Williams \& Wilkins, Baltimore.

[6] Saint-André, J.P., Valo, I. and Guyétant, S. (2000) Immunohistochimie des tumeurs neuro-endocrines. Annales de Pathologie, 20, S129-31.

[7] Oda, Y., Tanaka, Y., Naruse, T., Sasanabe, R., Tsubamoto, M. and Funahashi, H. (2002) Expression of somatostatin receptor and effects of somatostatin analog on pancreatic endocrine tumors. Surgery Today, 32, 690-694. http://dx.doi.org/10.1007/s005950200128

[8] Hauser, H., Wolf, G., Uranus, S. and Klimpfinger, M. (1995) Neuroendocrine tumours in various organ systems in a ten-year period. European Journal of Surgical Oncology, 21, 297-300. http://dx.doi.org/10.1016/S0748-7983(95)91624-5

[9] Modlin, I.M. and Sandor, A. (1997) An analysis of 8305 cases of carcinoid tumors. Cancer, 79, 813-829. http://dx.doi.org/10.1002/(SICI)1097-0142(19970215)79: 4<813::AID-CNCR19>3.0.CO;2-2

[10] Williams, E.D. and Sandler, M. (1963) The classification of carcinoid tumours. Lancet, 281, 238-239. http://dx.doi.org/10.1016/S0140-6736(63)90951-6

[11] Travis, W.D., Colby, T.V., Corrin, B., et al. (1999) Histological typing of lungand pleural tumours. WHO International Histological Classificationof Tumours, Springer, Berlin. http://dx.doi.org/10.1007/978-3-642-60049-4

[12] Solcia, E., Klöppel, G. and Sobin, L.H. (2000) Histological typing of endocrine tumours. WHO International Histological Classification of Tumours. Springer, Berlin. http://dx.doi.org/10.1007/978-3-642-59655-1

[13] Capella, C., Sessa, F., Cornaggia, M., La Rosa, S. and Uccella, S. (1999) Mixedexocrine-endocrine tumors of the gastro-intestinal tract. Revista española de Patología, 32, 466-467.

[14] Heymann, M.F., Joubert, M., Nemeth, J., Franc, B., Visset, J., Hamy, A., le Borgne, J., le Neel, J.C., Murat, A., Cordel, S. and le Bodic, M.F. (2000) Prognostic and immunohistochemical validation of the Capella classification of pancreatic neuroendocrine tumours: An analysis of 82 sporadic cases. Histopathology. 36, 421-432. http://dx.doi.org/10.1046/j.1365-2559.2000.00892.x

[15] Gumbs, A.A., Moore, P.S., Falconi, M. Bassi, C., Beghelli, S., Modlin, I. and Scarpa, A. (2002) Review of the clinical, histological and molecular aspects of pancreatic endocrine neoplasms. Journal of Surgical Oncology, 81, 45-53. http://dx.doi.org/10.1002/jso.10142

[16] Le Bodic, M.F., Heymann, M.F., Lecomte, M., Berger, N., Berger, F., Louvel, A., De Micco, C., Patey, M., De Mascarel, A., Burtin, F. and Saint-Andre, J.P. (1995) Immuno-histochemical study of 100 pancreatic tumors in 28 patients with Multiple Endocrine Neoplasia type 1. The American Journal of Surgical Pathology, 20, 1378-1384. http://dx.doi.org/10.1097/00000478-199611000-00009

[17] Komminoth, P. (1999) Review: Multiple endocrine neoplasia type 1, sporadic neuroendocrine tumors, and MENIN. Diagnostic Molecular Pathology, 8, 107-112. http://dx.doi.org/10.1097/00019606-199909000-00001

[18] Matias-Guiu, X. (1998) RET protooncogene analysis in the diagnosis ofmedullary thyroid carcinoma and muliple endocrine neoplasiatype II. Advances in Anatomic Pathology, 5, 196-201. http://dx.doi.org/10.1097/00125480-199805000-00058 